OPEN ACCESS

Edited by:

Andrea Cochis,

University of Eastern Piedmont, Italy

Reviewed by:

Jirî́ Gallo,

Palacký University, Olomouc, Czechia

Giuseppe Cappellano,

University of Eastern Piedmont, Italy

Elena Maria Varoni,

University of Milan, Italy

${ }^{*}$ Correspondence:

Cecilia J. Alves

cjmalves@ineb.up.pt

${ }^{\dagger}$ These authors have contributed equally to this work

Specialty section:

This article was submitted to

Biomaterials,

a section of the journal

Frontiers in Materials

Received: 11 April 2020

Accepted: 23 July 2020

Published: 28 August 2020

Citation:

Couto $M$, Vasconcelos $D P$, Sousa DM, Sousa B, Conceição $F$,

Neto E, Lamghari M and Alves CJ (2020) The Mechanisms Underlying

the Biological Response to Wear

Debris in Periprosthetic Inflammation.

Front. Mater. 7:274

doi: $10.3389 /$ fmats.2020.00274

\section{The Mechanisms Underlying the Biological Response to Wear Debris in Periprosthetic Inflammation}

\author{
Marina Couto ${ }^{1,2+}$, Daniela P. Vasconcelos ${ }^{1,2+}$, Daniela M. Sousa ${ }^{1,2}$, Beatriz Sousa $a^{1,2,3}$, \\ Francisco Conceição ${ }^{1,2,4}$, Estrela Neto ${ }^{1,2}$, Meriem Lamghari ${ }^{1,2,4}$ and Cecilia J. Alves ${ }^{1,2 *}$ \\ ${ }^{1}$ Instituto de Investigação e Inovação em Saúde da Universidade do Porto- Associação, Porto, Portugal, ${ }^{2}$ Instituto \\ de Engenharia Biomédica, Universidade do Porto, Porto, Portugal, ${ }^{3}$ Faculdade de Engenharia, Universidade do Porto, \\ Porto, Portugal, ${ }^{4}$ Instituto Ciências Biomédicas Abel Salazar, Universidade do Porto, Porto, Portugal
}

Joint replacement surgery is the gold-standard therapeutic approach to treat patients with end-stage hip and knee arthritis, providing pain relief and joint function recovery. Despite the improvements in implant design and surgical techniques, revisions after total joint replacement are expected to grow. The periprosthetic inflammation, featured by the sustained inflammatory response to the implant debris, elicits the activation of osteoclasts and consequent periprosthetic osteolysis (PPOL), ultimately leading to implant aseptic loosening, which is the most common cause of long-term implant failure. There are currently no effective strategies to control periprosthetic inflammation, and long-term implant survival remains a major challenge in orthopedics. A broad knowledge of the mechanisms underlying the biological response to implant debris would support the development of novel and effective pharmacological strategies to manage PPOL and promote implant lifespan. In this review, a detailed description of the cellular and the molecular mechanisms underlying the biological response to implant debris is provided, highlighting the most recent findings. Furthermore, we reviewed novel therapeutic strategies that are being investigated to prevent inflammatory periprosthetic osteolysis.

Keywords: orthopedic implants, implant wear particles, periprosthetic inflammation, osteolysis, aseptic loosening

\section{INTRODUCTION}

Joint replacement surgery, one of the most successful procedures in orthopedics, remains the ultimate option to relieve uncontrolled pain and re-establish joint function in end-stage hip and knee arthritis (Learmonth et al., 2007). A regression analysis with age, gender, race and/or ethnicity, census region, and year as covariates, performed using data from the US National Center for Health Statistics, indicate that the number of hip and knee arthroplasties is estimated to grow $174 \%$ to 572,000 procedures and $673 \%$ to 3.48 million, respectively, by 2030 (Kurtz et al., 2007). The same study projects that about 7 and $15 \%$ of knee and hip arthroplasties, respectively, are still expected to fail, causing the need for a revision surgery (Kurtz et al., 2007). The revision surgeries, in addition to the significant healthcare costs, are associated with a high risk of infection and poor clinical outcomes (Vanhegan et al., 2012; Weber et al., 2018).

The slow progressive inflammatory response to the implant-derived wear particles is the hallmark of periprosthetic osteolysis (PPOL) and subsequent implant aseptic loosening (AL) 
(Cobelli et al., 2011; Parvizi, 2015; Sukur et al., 2016), a major cause for long-term implant failure (Sharkey et al., 2014; Thiele et al., 2015).

Periprosthetic inflammation is characterized by an innate immune response that occurs due to macrophage reactivity to implant byproducts, resulting in the release of pro-inflammatory factors, activation of osteoclasts, and consequent osteolysis, thus leading to AL (Goodman et al., 2014; Athanasou, 2016; Gallo, 2019).

In the current scenario of increasing life expectancy and growing rate of joint replacement in the younger and more active population (Kurtz et al., 2009; Skytta et al., 2011; Katz, 2012), the long-term survival of joint replacement is a major challenge in orthopedics.

Biomaterials, such as metals, polymers, and ceramics, are currently used to fabricate joint replacement implants, and several bearing surfaces can be obtained by the combination of different materials. Despite the biocompatibility of the materials used and the improvement in the (i) implant designs, (ii) materials themselves, and (iii) surgical techniques, the repeated movement of the bearing surfaces under loading generates wear debris (e.g., wear particles and metal ions) that trigger an exacerbated biologic response (Gibon et al., 2017a,b). Particularly, polymeric and metal debris represent the major concerns.

There are currently no effective strategies for treating periprosthetic inflammation. A clear understanding of the biological mechanisms underlying the response to implant debris would support the development of non-surgical biological approaches to manage inflammatory periprosthetic bone loss and promote implant survival.

Here we presented a detailed review of the pathways involved in the biological response to implant debris, emphasizing the recent findings. In addition, we also reviewed potential therapeutic strategies, which are under investigation, to control inflammation-induced PPOL.

\section{BIOMATERIALS USED IN JOINT REPLACEMENT IMPLANTS}

The selection of a biomaterial for an implant relies on critical aspects, in which the biological requirements are added to the chemical, mechanical, and physical requests. Concepts such as biocompatibility, bioactivity, and osteoinduction are considered as major players in the process of development and selection of a biomaterial for orthopedic implants (Navarro et al., 2008). Metals, polymers, and ceramics are the three categories of materials currently used to design joint replacement implants.

Titanium and its alloys and cobalt-chrome (Co-Cr) alloys are the metals used for their excellent mechanical and corrosion properties (Prasad et al., 2017). Nevertheless, the release of ions and wear particles from the metallic materials is a matter of concern (Hamidi et al., 2017). Despite their excellent biocompatible properties, the ions and the wear particles released from metal alloys may activate an immune response that, as will be discussed in section "Biological Mechanisms Underlying the
Response to Implant Wear Debris," can promote osteolysis and, eventually, implant AL.

The ultrahigh molecular weight polyethylene (UHMWPE) is the most commonly used polymer in the design of orthopedic implants (Alothman et al., 2014). It has been considered an exceptional material to be employed in coupling bearing surfaces with metals or ceramics and is highly biocompatible and very resistant to corrosion (Bracco et al., 2017). The release of wear particles is the major source of concern associated with UHMWPE. Despite the reduction in mechanical properties, cross-linking the material has allowed to partially overcome this issue. Highly cross-linked UHMWPE was introduced in the 1990s, and long-term clinical studies showed significant less wear when compared with conventional polyethylene (PE) (Shi et al., 2019).

The biocompatibility features of bioceramics make them very important candidates to be used in orthopedic implants (Campbell et al., 2004). Bioceramics can behave as inert or bioactive materials in an osseous environment, presenting osteoconductive properties and promoting the fixation of joint prostheses (Navarro et al., 2008). Alumina and zirconia have been used to replace metallic materials. Alumina offers lower friction and constant wear, and zirconia presents minor wear, in addition to its strength (Gamble et al., 2017). To overcome inherent disadvantages, such as high brittleness and high elastic modulus, these materials have been combined in order to develop zirconia-toughened alumina. The base of alumina provides high hardness to the material and zirconia promotes resistance to crack propagation (De Aza et al., 2002; Tuan et al., 2002).

Presently, several options of bearing surfaces for joint replacement implants are available. For total hip replacement, surgeons choose between ceramic-on-ceramic (CoC), ceramicon-polyethylene (CoPE), and metal-on-polyethylene (MoPE), each presenting specific advantages and disadvantages (Gallazzi, 2018). Metal-on-metal bearing surfaces are no longer considered as an option due to the high rate of failure and the serious adverse biological response to the metallic wear debris released (Campbell, 2010; Gill et al., 2012; Gallazzi, 2018). Acetabular liners are commonly made of PE, either UHMWPE or XLPE or ceramics (Gallazzi, 2018). Ceramics and metal alloys are used to manufacture the heads. The bearing surfaces containing acetabular liners made of conventional PE (both MoPE and CoPE) are associated with wear particle release and osteolysis (Gallazzi, 2018). This drawback is less important for XLPE (Sakellariou et al., 2013). CoC bearing surfaces are between the best-performing bearing surfaces, with very low wear rates and high biocompatibility (Petsatodis et al., 2010; Kang et al., 2015). However, the brittleness of the material that increases the risk of breakage (Howard et al., 2017) and the noise from the implant such as squeaking (Swanson et al., 2010) are still important disadvantages of the CoC bearing surfaces. Regarding bearing surfaces in knee replacement implants, UHMWPE of the tibial insert can articulate against metal or ceramic femoral components (Oonishi et al., 2009; Inacio et al., 2013), although ceramic femoral components are yet rarely used in clinical practice (Solarino et al., 2017). 
Overall, the choice of the best coupling bearing surfaces requires a deep understanding of the features of each bearing surface and a profound knowledge of the patients' specific characteristics and needs.

\section{COMMON CAUSES OF JOINT REPLACEMENT IMPLANT FAILURE}

The expansion of novel implant devices has been promoting the longevity of orthopedic implants. However, patients submitted to arthroplasties are still facing the multiple risk factors of implant failure. The patients' comorbidities (such as obesity, rheumatoid arthritis, and diabetes mellitus) and the inadequate surgical techniques may cause post-operative complications (e.g., bleeding, wound dehiscence, and infection) (Haleem, 2018; Ravi et al., 2019). When not suitable for pharmacological treatment, these complications compromise, at the early stages, the success of arthroplasty, and a revision surgery may be required (Delaunay et al., 2013).

Periprosthetic infection is the most common and serious complication that can occur at the early stages after a joint replacement (Sharkey et al., 2014; Thiele et al., 2015; Lum et al., 2018), often demanding multiple additional surgeries to replace the infected implant. Although the risk of infection is higher during the first weeks after surgery [mostly associated with the patients' risk factors and inadequate surgery techniques (Haleem, 2018)], periprosthetic infection can occur at later stages. Infection in adjacent tissues can promote the entrance of bacteria in the bloodstream, increasing the risk of implant colonization and infection at any time post-surgery (Feng et al., 2016). The administration of antibiotics often fails to eliminate the infection, making the need for complex subsequent surgical procedures inevitable (Li et al., 2019).

Concerning the long-term implant failures, $\mathrm{AL}$ becomes the most common cause of orthopedic implant revision surgeries (Sharkey et al., 2014; Thiele et al., 2015). The causes for AL change overtime after arthroplasty; at the early stages, it is mostly associated with implant fixation failure, while at the later stages, it is related with wear particle-associated osteolysis. The regular use of joint replacement prostheses causes the release of small debris that stimulate an inflammatory response and subsequent periprosthetic bone osteolysis (Gallo, 2019). Currently, revision surgery is the only procedure available to manage AL. Nevertheless, revision surgeries have been associated to high clinical and surgical risks and are not as effective as the primary surgeries, comprising lower outcomes and higher infection rates (Weber et al., 2018).

\section{BIOLOGICAL MECHANISMS UNDERLYING THE RESPONSE TO IMPLANT WEAR DEBRIS}

Biomaterial implantation gives rise to a host response to the foreign material that will determine the integration and the biological performance of the implant. The molecular patterns and the degradation products released by implanted devices can stimulate the immune system (Kubes, 2020). Upon biomaterial implantation, a sequence of events is initiated, beginning with an injury, followed by blood - material interactions, provisional matrix formation, acute inflammatory response that may lead to chronic inflammation, granulation tissue development, foreign body reaction, and fibrosis/fibrous capsule development, impairing the implant function (Anderson et al., 2008).

During the last years, we have witnessed a change in the concept of what is an ideal biomaterial/implant. Instead of being a material design to diminish host responses, biomaterials are now developed to trigger desired immunological responses, improving implant performance, its integration, and subsequent tissue repair (Ning et al., 2016). With the improvement of biomaterials, the half-life of total hip and knee arthroplasty has considerably increased. Recent systematic reviews and metaanalysis, with more than 15 years of follow-up, concluded that total hip and knee replacement can be expected to last 25 years in 58 and $82 \%$ of patients, respectively (Evans et al., 2019a,b). However, the slow and progressive inflammatory response at the bone/implant interface to the implant debris released from the bearing surfaces causes PPOL, a major threat to long-term implant survival.

Although implant debris can initiate an innate inflammatory response acting on numerous cells including monocytes, fibroblasts, osteoblasts, osteoclasts, and mesenchymal stem cells (MSCs), resident macrophages are the key population to eliminate wear particles (Nich et al., 2013). In some circumstances, the adaptive immune system can also be activated, primarily in response to metal ions associated with a hypersensitivity reaction to metals (Goodman, 2007; Pajarinen et al., 2014; Schalock, 2017). The activation of macrophages is still the dominant mechanism in periprosthetic inflammation (Athanasou, 2016).

Macrophage reactivity, upon activation by wear particles (Figure 1), is driven by the chemical and the physical features of the particles and is determined by pattern recognition receptors (PRRs), which results in the release of pro-inflammatory cytokines [e.g., tumor necrosis factor (TNF)- $\alpha$, IL-1 $\beta$, IL-6, prostaglandin E (PGE)-2), growth factors (macrophage colony stimulating factor $1-\mathrm{M}-\mathrm{CSF}$ ), pro-osteoclastic factors (receptor activator of nuclear factor kappa B ligand-RANKL), and chemokines (e.g., IL-8, macrophage inflammatory proteinMIP-1 $\alpha$, monocyte chemoattractant protein-MCP-1)], leading to the systemic recruitment of more macrophages and osteoclast precursors, promoting inflammation and osteolysis (Landgraeber et al., 2014).

It is well accepted that the inflammatory response to the implant particles leads to osteoclast formation through progenitor recruitment and up-regulation of RANKL (Fisher, 2005; Holding et al., 2006; Abu-Amer et al., 2007; Landgraeber et al., 2014). The release of TNF- $\alpha$ and IL-1 $\beta$ by macrophages in response to wear particles promotes the expression of RANKL and suppresses the expression of osteoprotegerin (OPG) by the osteoblasts and fibroblasts (Lin et al., 2014; Kandahari et al., 2016). RANKL binds to the RANK expressed on osteoclast precursors, activating signaling pathways such as nuclear factor 


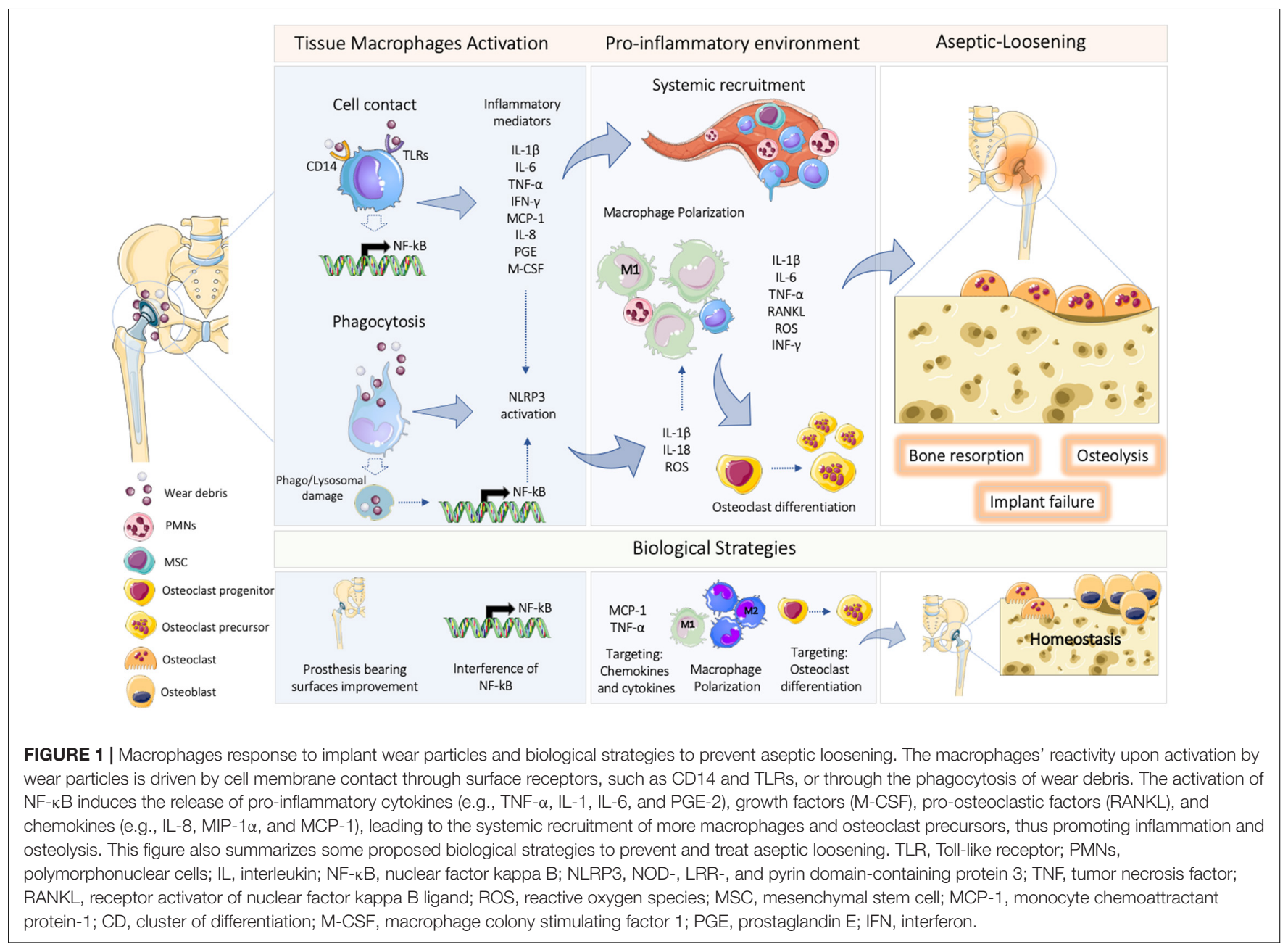

kappa-light-chain-enhancer of activated B cells (NF-кB) and mitogen-activated protein kinase (MAPK), therefore stimulating osteoclastogenesis and excessive bone resorption activity and ultimately leading to implant loosening (Purdue et al., 2007).

Macrophages are remarkable plastic cells with different functions and functional states, which are specified by the complex interplay between microenvironmental signals and a differentiation program that determines the macrophage identity. Two well-established polarized phenotypes are often referred to as classically activated macrophages (M1) and alternatively activated macrophages (M2). The M1 macrophages are characterized by the production of pro-inflammatory cytokines, namely, TNF- $\alpha$, IL-1, and IL-6, express inducible nitric oxide synthase, and are linked to T helper 1 (Th1) type of immune response (Murray, 2017). M2 macrophages have associated antiinflammatory cytokines, such as IL-4, IL-10, and IL13, express mammalian chitinase $\mathrm{Ym} 1$ and arginase 1 , and are related to $\mathrm{T}$ helper 2 (Th2) type of immune response (Murray, 2017).

M1 macrophages have been found in high concentrations in periprosthetic tissues from AL patients (Rao et al., 2012). Indeed PMMA (resulting from the bone cement) and UHMWPE particles were shown to polarize macrophages toward an
M1 phenotype in vitro (Rao et al., 2012; Antonios et al., 2013; Jiang et al., 2016). Mahon et al. (2018) reported that the preferential polarization toward M1 phenotype induced by PMMA particles is dependent on the activation of membrane proximal kinase, spleen tyrosine kinase (Syk), and members of MAPK family. Moreover, they show that pre-treatment with Syk or MAPK inhibitors prevented M1 polarization and reduced the production of pro-inflammatory mediators implicated in PPOL and osteoclast differentiation (Mahon et al., 2018).

The precise mechanisms by which wear particles are recognized and induce macrophage activation have not been fully elucidated. Recent studies have shown that wear debris act as danger signals or alarmins and are recognized by cell membrane contact through surface receptors or after phagocytosis by several PRRs (Goodman, 2014). PRRs can identify a myriad of stimuli, including pathogen-associated molecular patterns (PAMPs) and damage-associated molecular patterns (DAMPs). PAMPs are exogenous molecules derived from bacteria, virus, and fungi (Medzhitov and Janeway, 1997). DAMPs are produced during tissue damage or homeostasis disturbances and include endogenous intracellular molecules [heat-shock protein and high 
mobility group protein (HMGB1)], components of extracellular matrix or released by necrotic cells and activated leukocytes (Matzinger, 1994; Venereau et al., 2015).

Based on location, PRRs can be subdivided into two major classes: (i) Toll-like receptors (TLRs) and C-type leptin receptors, which are transmembrane proteins, and (ii) the retinoic acidinducible protein 1 (RIG)-1-like receptors and the NOD-like receptors (NLRs), which are located intracellularly (Kumar et al., 2011). Evidence supports the DAMPs and the activation of TLRs as dominant mechanisms in macrophage reactivity to implant particles; other mechanisms such as apoptosis, bone catabolism, and hypoxia responses are also involved (Catelas et al., 1999a; Samelko et al., 2013).

The signaling pathways activated by TLRs are divided into myeloid differentiation factor 88 (MyD88)-dependent and MyD88-independent pathways. The MyD88-dependent pathways are the main downstream signaling shared by almost all TLRs, except TLR-3. MyD88 signaling leads to the activation of NF$\kappa \mathrm{B}$ and activating protein-1, responsible for the production of pro-inflammatory cytokines (e.g., TNF- $\alpha$, IL-1, and IL-12) (O'Neill et al., 2013). The involvement of TLRs in the reactivity to implant particles has been demonstrated both in patient tissues and in animal models. TLRs are highly expressed by the infiltrated macrophages in the periprosthetic tissues of $\mathrm{AL}$ patients (Takagi et al., 2007; Lahdeoja et al., 2010; Pajarinen et al., 2010). In in vitro cultures of macrophages, the inhibition of MyD88 signaling resulted in the decrease of the inflammatory response to PMMA particles (Pearl et al., 2011). In the same line, MyD88 knockout mice display a reduced inflammatory response to PMMA particles (Pearl et al., 2011).

The NOD-, LRR- and pyrin domain-containing protein 3 (NLRP3/NALP3) inflammasome has also been implicated in the biological response to implant debris (Takagi et al., 2007; Caicedo et al., 2009). The NLRP3 inflammasome is an intracellular multi-protein complex activated upon cellular infection (PAMPs) or stress (DAMPs), triggering the maturation of the highly pro-inflammatory cytokines IL-1 $\beta$ and IL-18 (Martinon et al., 2002; Tschopp, 2010). NLRP3 activation requires a two-step signal. The first one, "priming signal," leads to the activation of NF- $\mathrm{B}$; the second step of the signal is responsible for the oligomerization of NLRP3 through the recruitment of procaspase-1 via the adaptor molecule apoptosis-associated specklike protein containing a CARD (ASC) and the cleavage of cytokine precursors, leading to the maturation and the release of IL-1 $\beta$ and IL-18 (Tschopp, 2010).

The phagocytosis of wear debris by macrophages has been shown to activate the NLRP3 inflammasome pathway, leading to caspase- 1 activation, pro-IL- $1 \beta$ cleavage, and mature IL-1 $\beta$ release, a critical cytokine for osteolysis induction (Shiratori et al., 2018). Metal ions and particles were shown to stimulate IL-1 $\beta$ secretion from human macrophages via inflammasome activation [i.e., nicotinamide adenine dinucleotide phosphate (NADPH)-, caspase- 1-, Nalp3-, and ASC-dependent] (Caicedo et al., 2009). Regarding this, CoCrMO-alloy particles were reported to stimulate inflammasome through lysosomal destabilization mechanisms in macrophages (Caicedo et al., 2013). Mice lacking caspase-1, the sole effector of the NALP3 inflammasome, also showed reduced PMMA particle-induced osteolysis (Burton et al., 2013). The presence of NLPR3 and their related molecules (caspase-1 and ASC) was detected in periprosthetic tissues (Takagi et al., 2007; Naganuma et al., 2016), ultimately supporting the involvement of NLRP3 inflammasome activation on the host response to implant debris. The continued investigation into how wear debris activate the inflammasome is therefore of great interest.

Differences in PPOL have been observed among individuals, and it is predicted to be associated with genetic variations (Gordon et al., 2010; Del Buono et al., 2012; MacInnes et al., 2015). As recently reviewed by Jagga et al. (2019), candidate gene studies show single nucleotide polymorphisms (SNPs) in several genes involved in both inflammatory signaling and bone turnover pathways in the context of PPOL (Jagga et al., 2019). SNPs have been observed in genes such as TNF$\alpha$, IL-1, MMPs, OPG, RANK, and RANKL (Jagga et al., 2019). Nevertheless, the functional effects of SNPs need to be investigated.

It is also known that different implant wear particles and their physical and chemical properties induce specific macrophage responses. In the following sections, we describe the inflammatory mechanisms triggered by wear debris released by the different materials used in the design of joint replacement implants: (i) polymers, (ii) metals, and (iii) ceramics.

\section{Polymer Wear Particles}

The macrophage reactivity to implant particles of polymers such as UHMWPE was shown to involve the activation of TLR signaling (Maitra et al., 2009; Paulus et al., 2014; Valladares et al., 2014). The specific involvement of TLR2 and TLR4 has been suggested in UHMWPE particle-induced osteolysis. UHMWPE induced the up-regulation of TLR2 and TLR4 in a calvarial mouse model (Valladares et al., 2014) and the up-regulation of TLR2 in a mouse model of intraarticular injection (Paulus et al., 2014). Moreover, in addition to the activation of TLR1/2 signaling pathways, UHMWPE particles also trigger the NLRP3 inflammasome through lysosomal damage (Maitra et al., 2009).

A transcriptional profiling analysis of human macrophages stimulated by UHMWPE particles revealed an up-regulation of pro-inflammatory mediators, in agreement with the previous studies, including CCL2, CCL3, CCL4, IL-8, CCL20, TNF- $\alpha$, IL-1 $\beta$, and IL-6, and genes involved in osteoclastogenesis and bone resorption, such as CCL3, CCL4, IL-8, CCL20, M-CSF, and MMPs (Terkawi et al., 2018). Overall, in this study, it was shown that macrophages elicited both inflammatory and osteoclastogenesis-related genes in response to UHMWPE particles, and importantly, TLR signaling was identified as being involved in the inflammatory and osteolytic response (Terkawi et al., 2018).

The PMMA particles have also been shown to be involved in the stimulation of osteoclastogenesis and osteolysis (Quinn et al., 1992; Sabokbar et al., 1998). These particles promoted 
the release of IL- $1 \beta$ and TNF- $\alpha$ from mouse macrophages (Antonios et al., 2013) and stimulated the production of MCP-1 and, by this way, the recruitment of more macrophages and MSCs (Huang et al., 2010). As previously mentioned, TLR signaling was demonstrated to be involved in macrophage reactivity to PMMA particles (Pearl et al., 2011). The inhibition of MyD88 decreases PMMA particle-induced production of TNF- $\alpha$ in mouse macrophages, and mice lacking the expression of MyD88 developed less PMMA-induced osteolysis (Pearl et al., 2011). The NALP3 inflammasome was also shown to have a critical contribution to PMMA particle-induced osteolysis. Burton et al. (2013) reported that PMMA particles induce caspase-1-dependent release of IL-1 $\beta$ from human monocytes and mouse macrophages and that this is reversed by the inhibition of the NALP3 inflammasome. They also reported that mice lacking caspase-1, the effector of the NALP3 inflammasome, present reduced PMMA-induced calvarial osteolysis (Burton et al., 2013). Recently, AbuAmer et al. (2019) reported that PMMA particles increase vascular endothelial growth factor (VEGF) expression and vascularization in a mouse calvarial model, and the inhibition of VEGF reduces TNF expression and osteoclastogenesis, highlighting the role of angiogenesis in PMMA particle-induced inflammatory osteolysis.

\section{Metal Wear Debris}

Generation of metallic debris is still a matter of great concern regarding PPOL. In in vitro and in vivo studies, cobalt alloy debris was shown to elicit inflammasome danger signaling, from initial lysosomal destabilization and NADPH oxidase induction of reactive oxygen species (ROS) to NLRP3-ASC oligomerization and caspase-1 conversion of pro-IL-1 $\beta$ and pro-IL-18 into mature IL-1 $\beta$ and IL-18 (Caicedo et al., 2013; Samelko et al., 2016). On the other hand, the involvement of TLR signaling in macrophage reactivity to cobalt particles has remained controversial. Cobalt and nickel metal ions were shown to facilitate TLR4 activation (Raghavan et al., 2012; Oblak et al., 2015). However, Samelko et al. (2016) reported that cobalt alloy particles do not preferentially activate TLR4-induced inflammation compared with NLRP3 inflammasome danger signaling (IL-1 $\beta$ ) in in vitro cultures of mouse and human macrophages. Moreover, the authors demonstrated that the inhibition of TLR4 did not decrease the inflammatory response (Samelko et al., 2016). In the same line, a TLR4-independent cobalt alloy-induced extreme inflammatory bone loss was observed in a mouse calvarial model; however, the blockage of the inflammasome pathway completely suppressed the innate inflammatory response to cobalt alloy particles (Samelko et al., 2016). The involvement of other specific toxicity responses, such as hypoxia, has been reported. Hypoxia-like responses were evaluated in human macrophages after challenge with cobaltalloy particles, and the levels of HIF- $1 \alpha$, VEGF, TNF- $\alpha$, and ROS were found to be up-regulated (Samelko et al., 2013). The up-regulation of HIF-1 $\alpha$ was also observed in periprosthetic tissues after the failure of MoM hip arthroplasties (Samelko et al., 2013).
Titanium implant particles are highly recognized to induce a pronounced macrophage inflammatory response, with upregulation of pro-inflammatory cytokines, mainly IL-1 $\beta$, IL6, and TNF- $\alpha$ (Eger et al., 2017, 2018), and activation of NLRP3 inflammasome through the release of active adenosine triphosphate (Baron et al., 2015). Moreover, it was shown that the IL-1 $\beta$ up-regulation induced by titanium and chromium particles in human macrophages is dependent on NLRP3 inflammasome activation that, in turn, is dependent of TNF- $\alpha$ priming signal (Jamsen et al., 2020).

Adding to the innate inflammatory response, it has been speculated that a delayed type of hypersensitivity-like reaction via $\mathrm{T}$ lymphocyte activation, though infrequent, could play a role in AL (Goodman, 2007; Pajarinen et al., 2014; Schalock, 2017). This hypothesis is based on the presence of $T$ lymphocytes in periprosthetic tissues and on the ability of metal ions to activate type-IV hypersensitivity by acting as haptens (Granchi et al., 2018). Recently, it was shown that the number of $\mathrm{T}$ lymphocytes increases in periprosthetic tissues with increasing time from surgery and the growing concentration of metals (Hobza et al., 2020).

The activation of macrophage by cobalt-alloy particles resulted in a $\mathrm{T}$ helper 17 (Th17) cell inflammatory response, which is directly associated with the risk of osteolysis development (Chen et al., 2017). However, in a study using a mouse model, the intraarticular injection of CoCrMo particles induced a significantly enhanced pro-inflammatory cytokine expression (TNF- $\alpha$, IL-6, and IL-1 $\beta$ ) when compared to the intraarticular injection of CoCrMo ions (Cheng et al., 2020). On the other hand, the expression of CD3-positive cells in the synovial membrane of mouse knee did not increase in any of the groups (Cheng et al., 2020). In the same line, data from an epidemiologic study showed that patients with MoM or MoP implants displayed a decrease in blood $\mathrm{T}$ lymphocytes despite an increase in the serum level of chromium and cobalt (Granchi et al., 2003). Overall, whether adaptive immune response contributes to the $\mathrm{AL}$ induced by metal particles and metal ions is still a matter of intense debate, and more studies are needed to clarify this subject.

\section{Ceramic Wear Particles}

$\mathrm{CoC}$ implants display minimal wear debris generation, with a limited incidence of osteolysis, and long-term implant survival rates, being proposed as the best option for young and active patients (Hamadouche et al., 2002; Hannouche et al., 2005). Nevertheless, studies on the toxicity of ceramic particles have been developed. Alumina and zirconia, the common ceramics used in joint implants, have been shown to have low immunotoxicity. In studies evaluating the in vitro effect of size and concentration of ceramic particles $\left(\mathrm{Al}_{2} \mathrm{O}_{3}\right.$ and $\mathrm{ZrO}_{2}$ ) in macrophages, it was shown that macrophage death increased with particle size and concentration; cell death was still considered to be very low (Catelas et al., 1999b, 1998). Moreover, the release of TNF- $\alpha$ increased with particle concentrations but was lower when compared with the levels induced by polymeric particles (Catelas et al., 1999b, 1998). In other studies, alumina particles were shown to have only limited capacity to stimulate human macrophage release of IL-1 $\beta$ and MCP-1 
(Kaufman et al., 2008), and even high concentrations of ceramic particles only induced a mild up-regulation of mRNA expression of RANKL, OPG, and TNF- $\alpha$ (Bylski et al., 2009). Zirconia particles were shown to induce the up-regulation of TLR3, TLR7, and TLR10; however, these had only a slight influence on the production of TNF- $\alpha$ and IL-1 $\beta$ (Lucarelli et al., 2004). Overall, ceramic particles have been reported to induce limited macrophage reactivity.

Despite the efforts made to decrease the generation of wear particles and the impact of AL, through the improvement of the materials, the implant design, the surgical techniques, and the peri-operative rehabilitation, long-term implant survival continues to be a major challenge. Further research is still needed to allow a comprehensive understanding of the mechanisms underlying the biological response to implant wear particles, which will support the development of non-surgical therapeutic modalities to control periprosthetic inflammation and the consequent osteolysis.

\section{POTENTIAL BIOLOGICAL STRATEGIES TO PREVENT ASEPTIC LOOSENING}

Multiple pharmacological strategies have been investigated as putative approaches to mitigate or reverse the implant particleinduced osteolysis. These strategies include the modulation of the inflammatory response (e.g., the blockage of pro-inflammatory cytokines and the modulation of macrophage polarization and NF- $\mathrm{B}$ pathway) and the modulation of the activity of osteoclasts (Figure 1).

\section{Bisphosphonates as a Strategy to Modulate Osteoclast Activity}

To avoid bone resorption, the osteoclast activity can be modulated using bisphosphonates. These drugs inhibit osteoclasts activity, suppress the differentiation of osteoclast precursors, and can also induce macrophage apoptosis (Moreau et al., 2007).

Pamidronate, a member of the bisphosphonate family, was shown to inhibit UHMWPE-induced TNF- $\alpha$ release from mouse macrophages and to induce macrophage apoptosis (Huk et al., 2003). Moreover, pamidronate suppressed the PMMAinduced bone resorption in a co-culture model of rat calvaria and macrophages (Horowitz et al., 1996). In the same line, bisphosphonate disodium ethane-1,1-diphosphonate was shown to abolish the differentiation of osteoclast precursors and bone resorption in a co-culture system of mouse monocytes and foreign body macrophages (derived from granulomas formed by a subcutaneous implantation of particles of PMMA, UHMWPE, or titanium) with osteoclasts seeded on bone slices (Pandey et al., 1996).

A meta-analysis of clinical trials of the post-operative administration of bisphosphonates supports short- and midterm anti-osteolytic effects on periprosthetic bone following arthroplasty (Prieto-Alhambra et al., 2014; Shi et al., 2018a; Su et al., 2018), indicating the beneficial effects of bisphosphonates in reducing mechanically induced bone resorption due to prosthesis insertion. Importantly, bisphosphonates were shown to reduce periprosthetic osteolysis also at later periods after total joint arthroplasty (5 to 10 years), and this is putatively related with effects on periprosthetic inflammation-induced osteolysis (Shi et al., 2018b).

By delaying or preventing bone resorption, bisphosphonates may be a beneficial strategy for preventing AL due to PPOL. However, adverse effects such as pathologic osteonecrosis of the jaw, femoral fracture, and impairment of fracture healing may hamper bisphosphonates' clinical application in AL context (Maalouf, 2012).

\section{The Targeting of the NF-кB Pathway}

The RANKL is a receptor-ligand released from activated cells during the inflammatory process and induces osteoclastogenesis and bone resorption (Wada et al., 2006).

The NF- $\kappa$ B pathway is activated in macrophages and osteoclasts when exposed to implant wear particles (Rao et al., 2012 ), supporting that the modulation of NF- $\kappa$ B signaling can be a strong strategy to mitigate osteolysis.

Ulrich-Vinther et al. (2002) reported in a titanium-implanted mouse model that the soluble OPG protein, which acts as a decoy receptor by binding to RANK, reducing its bioavailability, decreased the number of osteoclasts and the bone resorption. In the same line, the target of the NF- $\mathrm{B}$ pathway with the NF-кB decoy oligodeoxynucleotide (ODN), which inhibits this transcription factor from binding to the promoter regions of targeted genes, was also shown to mitigate wear particle-induced osteolysis. In a mouse model of continuous femoral particle infusion, the local delivery of NF- $\kappa$ B decoy ODN reversed the bone loss induced by UHMWPE particles and inhibited macrophage infiltration and osteoclast number (Lin et al., 2016). The local injections of ODN in a mouse calvarial model also reduced the UHMWPEinduced expression of TNF- $\alpha$ and RANKL and increased the expression of anti-inflammatory and anti-resorptive cytokines (Sato et al., 2015).

The modulation of the $\mathrm{I}_{\mathrm{K}} \mathrm{B}$ kinase (IKK) has been highlighted as another potential strategy to inhibit the NF-кB pathway. The reduction of the IKK complex assembly, through a short peptide named NEMO-binding domain (NBD), led to the inhibition of NF- $\mathrm{B}$ activation, preventing RANKL-induced osteoclastogenesis (Karin et al., 2004). Specifically, NBD peptide was reported to inhibit PMMA-induced NF- $\kappa \mathrm{B}$ activation in vitro and inhibited the PMMA-stimulated osteoclastogenesis and decreased PMMA-induced inflammatory response and osteolysis in a mouse calvarial model (Clohisy et al., 2006). Also in a mouse calvarial model, the intraperitoneal injections of RANK:FC fusion protein, a recombinant RANKL antagonist, inhibit the osteoclastogenesis and the bone resorption induced by titanium particles (Childs et al., 2002). More recently, it was shown that Tussilagone, a natural compound, impairs osteolysis by the inhibition of RANKL-mediated NF- $\kappa$ B and p38-mediated MAPK signaling pathways in a titanium particle-induced murine calvarial model (Hu et al., 2020).

Altogether these studies support the targeting of the NF-кB signaling pathway as a promising strategy to mitigate implant particle-induced inflammatory osteolysis, and further studies are needed to establish the efficacy and the safety of this strategy. 


\section{Modulation of Macrophage Polarization}

Despite the complexity of the mechanisms governing macrophage polarization, manipulation toward a more antiinflammatory phenotype emerges as a potential strategy to diminish implant particle-associated inflammation (Ribeiro-da-Silva et al., 2018; Goodman et al., 2020).

Several in vitro and in vivo studies showed that macrophage stimulation with IL-4 increases the expression of M2 markers. In PMMA-activated mouse bone marrow-derived macrophages, treatment with IL-4 reduced the TNF- $\alpha$ production (Antonios et al., 2013). This effect was more notorious when IL-4 was added before PMMA particles but was also observed when IL-4 was administrated concurrently or after the challenge with the PMMA particles (Rao et al., 2012; Antonios et al., 2013). Moreover, IL-4 treatment also decreased the production of TNF- $\alpha$, IL-1 $\beta$, and GM-CSF in PMMA-stimulated human macrophages (Trindade et al., 1999). A reduction in TNF- $\alpha$ and IL- 6 production was also observed in human macrophages exposed to titanium-alloy $\left(\mathrm{Ti}_{6} \mathrm{Al}_{4} \mathrm{~V}\right)$ particles and treated with IL-4 (Han, 2001). In the same study, treatment with IL-10 also reduced the production of these pro-inflammatory cytokines (Han, 2001).

In UHMWPE particle-induced osteolysis in the mouse calvarial model, daily treatment with IL-4 significantly decreased bone loss and M1/M2, RANKL/OPG, and TNF- $\alpha /$ IL-1ra ratios (Rao et al., 2013). The coating of implants with IL-4 resulted in a preferential macrophage polarization toward an M2 phenotype, in both in vivo and in vitro studies (Hachim et al., 2017; Yang et al., 2018), and in an enhanced expression of M2 markers such as IL-10, ARG-1, and platelet-derived growth factor-BB (Yang et al., 2018).

Lately, metformin, an anti-diabetic drug, was shown to promote the release of IL-10 from mouse bone marrow-derived macrophages exposed to UHMWPE particles (Yan et al., 2018). Metformin treatment also reduced the production of proinflammatory cytokines, osteoclastogenesis, and osteolysis and promoted IL-10 production and the polarization of macrophages toward a M2 phenotype in the UHMWPE particle-induced osteolysis mouse calvarial model (Yan et al., 2018).

In general, in vitro and in vivo studies support the modulation of macrophage polarization as a putative effective approach to mitigate implant wear particle-induced inflammation and subsequent osteolysis.

\section{Pharmacological Blockage of Pro-inflammatory Mediators}

As already described, the reactivity of macrophages to implant particles leads to the release of pro-inflammatory factors (cytokines, chemokines, prostaglandins, nitric oxide, and peroxide metabolic intermediates) that will elicit osteolysis and AL. The local inhibition of these pro-inflammatory mediators may reduce inflammation in the periprosthetic tissue. Between the pro-inflammatory mediators, TNF- $\alpha$ is critically involved in wear particle-induced osteolysis, and its inhibition has been investigated as a potential therapeutic strategy.
The antagonism of TNF- $\alpha$ with progranulin [a small antiinflammatory peptide that inhibits the binding of $\mathrm{TNF} \alpha$ to TNFR1/2 (Tian et al., 2014)] effectively inhibited titanium particle-induced inflammation in an air pouch model and osteoclastogenesis and osteolysis in vitro, ex vivo, and in vivo (Zhao et al., 2016). Moreover, it was shown that these effects were achieved primarily via inhibition of the TNF $\alpha / N F-\kappa B$ signaling pathway (Zhao et al., 2016). Etanercept, a soluble TNF$\alpha$ antagonist, was shown also to prevent titanium wear debrisinduced osteolysis in vitro and osteoclastogenesis and osteolysis in vivo (Childs et al., 2001).

Eger et al. (2018) showed, using the mouse calvarial model of titanium particle-induced osteolysis, that blocking TNF$\alpha$, IL-1 $\beta$, and IL-6 with anti-TNF $\alpha$ (adalimunab), anti-IL$1 \beta$ (anakinra), and anti-IL6 (tocilizumab) antibodies in vivo completely abolished titanium-induced osteolysis. Resveratrol, a natural compound with antioxidant, anti-inflammatory, and antitumor effects (Frojdo, 2008), reduced the titanium wear particle-induced oxidative stress in mouse macrophages, and this was accompanied by the reduction of TNF- $\alpha$ release and NF- $\kappa B$ phosphorylation (Luo et al., 2016). Overall, these studies support the inhibition of TNF- $\alpha$ as a putative therapeutic approach to control PPOL.

Further investigation is still deeply needed (i) to establish the effectiveness, safety, and translatability to clinics of the promising pharmacological strategies in ongoing research and (ii) to identify novel therapeutic targets. Importantly, while extensive literature on preclinical data is already available, only moderate clinical research has been performed (Schwarz, 2014). Moreover, studies in humans have mostly focused on the AL conditions, although a different inflammatory profile was observed between AL and non-AL stages of arthroplasty (Dyskova et al., 2019). Information on the time axis of the processes occurring in the periprosthetic tissues, from arthroplasty until the implant AL, will strengthen our understanding of the mechanisms driving inflammationinduced PPOL and further support the development of effective therapeutic approaches.

\section{CONCLUSION}

In the last decades, the biological response to implant wear debris has been investigated and macrophages were identified as the key cells. However, the precise mechanisms by which wear debris are recognized and induce macrophage activation have not been fully elucidated. The information gathered so far demonstrate that wear debris are recognized by several PRRs (e.g., TLRs and NLRs). Among the PRRs, the activation of TLRs has been identified as a dominant mechanism in macrophage reactivity to implant particles. The activation of the NLRP3 inflammasome has also been clearly implicated in this process. The trigger of these mechanisms generates an inflammatory environment that promotes periprosthetic osteolysis and AL.

There are currently no effective pharmacological strategies to manage periprosthetic inflammation. However, several therapeutic approaches are in ongoing research, namely, the (i) blockage of the NF- $\kappa B$ pathway, (ii) modulation of macrophage 
polarization toward an anti-inflammatory profile, and (iii) neutralization of TNF- $\alpha$ and other pro-inflammatory cytokines. Further research is still needed to confirm their efficacy, safety, and therapeutic potential in order to be translated to the clinics. Furthermore, a comprehensive understanding of the mechanisms underlying the biological response to implant wear particles will support the identification of novel targets for putative effective therapeutic methods to control periprosthetic inflammationinduced osteolysis.

\section{AUTHOR CONTRIBUTIONS}

$\mathrm{MC}, \mathrm{DV}$, and CA conceptualized this work and wrote the manuscript. DS, BS, FC, EN, and ML contributed to the

\section{REFERENCES}

Abu-Amer, W., Arra, M., Clohisy, J. C. F., Abu-Amer, Y., and Swarnkar, G. (2019). Targeting vascular endothelial growth factor ameliorates pmmaparticles induced inflammatory osteolysis in murine calvaria. Bone 123, 86-91. doi: 10.1016/j.bone.2019.03.025

Abu-Amer, Y., Darwech, I., and Clohisy, J. C. (2007). Aseptic loosening of total joint replacements: mechanisms underlying osteolysis and potential therapies. Arthritis Res. Ther. 9(Suppl. 1):S6. doi: 10.1186/ar2170

Alothman, O. Y., Fouad, H., Al-Zahrani, S. M., Eshra, A., Al Rez, M. F., and Ansari, S. G. (2014). Thermal, creep-recovery and viscoelastic behavior of high density polyethylene/hydroxyapatite nano particles for bone substitutes: effects of gamma radiation. Biomed. Eng. Online 13:125. doi: 10.1186/1475-925X-13125

Anderson, J. M., Rodriguez, A., and Chang, D. T. (2008). Foreign body reaction to biomaterials. Semin. Immunol. 20, 86-100. doi: 10.1016/j.smim.2007.11.004

Antonios, J. K., Yao, Z., Li, C., Rao, A. J., and Goodman, S. B. (2013). Macrophage polarization in response to wear particles in vitro. Cell Mol. Immunol. 10, 471-482. doi: $10.1038 / \mathrm{cmi} .2013 .39$

Athanasou, N. A. (2016). The pathobiology and pathology of aseptic implant failure. Bone Joint Res. 5, 162-168. doi: 10.1302/2046-3758.55.BJR-2016-0086

Baron, L., Gombault, A., Fanny, M., Villeret, B., Savigny, F., Guillou, N., et al. (2015). The nlrp3 inflammasome is activated by nanoparticles through atp, adp and adenosine. Cell Death Dis. 6:e1629. doi: 10.1038/cddis.20 14.576

Bracco, P., Bellare, A., Bistolfi, A., and Affatato, S. (2017). Ultra-high molecular weight polyethylene: influence of the chemical, physical and mechanical properties on the wear behavior. a review. Materials 10:791. doi: 10.3390/ ma10070791

Burton, L., Paget, D., Binder, N. B., Bohnert, K., Nestor, B. J., Sculco, T. P., et al. (2013). Orthopedic wear debris mediated inflammatory osteolysis is mediated in part by nalp3 inflammasome activation. J. Orthop. Res. 31, 73-80. doi: 10. $1002 /$ jor. 22190

Bylski, D., Wedemeyer, C., Xu, J., Sterner, T., Loer, F., and von Knoch, M. (2009). Alumina ceramic particles, in comparison with titanium particles, hardly affect the expression of rank-, tnf- alpha-, and opg-mrna in the thp- 1 human monocytic cell line. J. Biomed. Mater. Res. A 89, 707-716. doi: 10.1002/jbm.a. 31956

Caicedo, M. S., Desai, R., McAllister, K., Reddy, A., Jacobs, J. J., and Hallab, N. J. (2009). Soluble and particulate co-cr-mo alloy implant metals activate the inflammasome danger signaling pathway in human macrophages: a novel mechanism for implant debris reactivity. J. Orthop. Res. 27, 847-854. doi: 10. 1002/jor.20826

Caicedo, M. S., Samelko, L., McAllister, K., Jacobs, J. J., and Hallab, N. J. (2013). Increasing both cocrmo-alloy particle size and surface irregularity induces increased macrophage inflammasome activation in vitro potentially through lysosomal destabilization mechanisms. J. Orthop. Res. 31, 1633-1642. doi: 10. 1002/jor.22411 original draft preparation. All authors participated in the revision of the manuscript and read and approved the submitted version.

\section{FUNDING}

This work was financed by the project NORTE-01-0145FEDER-000012, supported by the Norte Portugal Regional Operational Program (NORTE 2020), under the PORTUGAL 2020 Partnership Agreement, through the European Regional Development Fund (ERDF). DS was a recipient of Fundação para a Ciência e a Tecnologia (FCT) post-doctoral fellowship (SFRH/BPD/115341/2016). FC was a recipient of FCT Ph.D. fellowship (SFRH/BD/128771/2017).

Campbell, P. (2010). Nanotoxicology of metal wear particles in total joint arthroplasty: a review of current concepts. J. Appl. Biomater. Biomech. 8, 1-6.

Campbell, P., Shen, F. W., and McKellop, H. (2004). Biologic and tribologic considerations of alternative bearing surfaces. Clin. Orthop. Relat. Res. 418, 98-111. doi: 10.1097/00003086-200401000-00017

Catelas, I., Huk, O. L., Petit, A., Zukor, D. J., Marchand, R., and Yahia, L. (1998). Flow cytometric analysis of macrophage response to ceramic and polyethylene particles: effects of size, concentration, and composition. J. Biomed. Mater. Res. 41, 600-607. doi: 10.1002/(sici)1097-4636(19980915)41:4<600::aid-jbm12<3.0. co; 2 -i

Catelas, I., Petit, A., Marchand, R., Zukor, D. J., Yahia, L., and Huk, O. L. (1999a). Cytotoxicity and macrophage cytokine release induced by ceramic and polyethylene particles in vitro. J. Bone Joint Surg. Br. 81, 516-521. doi: 10.1302/0301-620x.81b3.8737

Catelas, I., Petit, A., Zukor, D. J., Marchand, R., Yahia, L., and Huk, O. L. (1999b). Induction of macrophage apoptosis by ceramic and polyethylene particles in vitro. Biomaterials 20, 625-630. doi: 10.1016/s0142-9612(98)00214-2

Chen, F., Chen, R., Liu, H., Sun, R., Huang, J., Huang, Z., et al. (2017). Bmp7 ameliorates cobalt alloy particle-induced inflammation by suppressing th17 responses. APMIS 125, 880-887. doi: 10.1111/apm.12730

Cheng, X., Dirmeier, S. C., Hasselt, S., Baur-Melnyk, A., Kretzer, J. P., Bader, R., et al. (2020). Biological reactions to metal particles and ions in the synovial layer of mice. Materials 13:1044. doi: 10.3390/ma13051044

Childs, L. M., Goater, J. J., O’Keefe, R. J., and Schwarz, E. M. (2001). Efficacy of etanercept for wear debris-induced osteolysis. J. Bone Miner. Res. 16, 338-347. doi: 10.1359/jbmr.2001.16.2.338

Childs, L. M., Paschalis, E. P., Xing, L., Dougall, W. C., Anderson, D., Boskey, A. L., et al. (2002). In vivo rank signaling blockade using the receptor activator of nfkappab:Fc effectively prevents and ameliorates wear debris-induced osteolysis via osteoclast depletion without inhibiting osteogenesis. J. Bone Miner. Res. 17, 192-199. doi: 10.1359/jbmr.2002.17.2.192

Clohisy, J. C., Yamanaka, Y., Faccio, R., and Abu-Amer, Y. (2006). Inhibition of ikk activation, through sequestering nemo, blocks pmma-induced osteoclastogenesis and calvarial inflammatory osteolysis. J. Orthop. Res. 24, 1358-1365. doi: 10.1002/jor.20184

Cobelli, N., Scharf, B., Crisi, G. M., Hardin, J., and Santambrogio, L. (2011). Mediators of the inflammatory response to joint replacement devices. Nat. Rev. Rheumatol. 7, 600-608. doi: 10.1038/nrrheum.2011.128

De Aza, A. H., Chevalier, J., Fantozzi, G., Schehl, M., and Torrecillas, R. (2002). Crack growth resistance of alumina, zirconia and zirconia toughened alumina ceramics for joint prostheses. Biomaterials 23, 937-945. doi: 10.1016/s01429612(01)00206-X

Del Buono, A., Denaro, V., and Maffulli, N. (2012). Genetic susceptibility to aseptic loosening following total hip arthroplasty: a systematic review. Br. Med. Bull. 101, 39-55. doi: 10.1093/bmb/ldr011

Delaunay, C., Hamadouche, M., Girard, J., Duhamel, A., and So, F. G. (2013). What are the causes for failures of primary hip arthroplasties in france? Clin. Orthop Relat. Res. 471, 3863-3869. doi: 10.1007/s11999-013-2935-5 
Dyskova, T., Kriegova, E., Slobodova, Z., Zehnalova, S., Kudelka, M., Schneiderova, P., et al. (2019). Inflammation time-axis in aseptic loosening of total knee arthroplasty: a preliminary study. PLoS One 14:e0221056. doi: 10.1371/journal. pone.0221056

Eger, M., Hiram-Bab, S., Liron, T., Sterer, N., Carmi, Y., Kohavi, D., et al. (2018). Mechanism and prevention of titanium particle-induced inflammation and osteolysis. Front. Immunol. 9:2963. doi: 10.3389/fimmu.2018.02963

Eger, M., Sterer, N., Liron, T., Kohavi, D., and Gabet, Y. (2017). Scaling of titanium implants entrains inflammation-induced osteolysis. Sci. Rep. 7:39612. doi: 10. 1038/srep39612

Evans, J. T., Evans, J. P., Walker, R. W., Blom, A. W., Whitehouse, M. R., and Sayers, A. (2019a). How long does a hip replacement last? A systematic review and meta-analysis of case series and national registry reports with more than 15 years of follow-up. Lancet 393, 647-654. doi: 10.1016/S0140-6736(18)31665-9

Evans, J. T., Walker, R. W., Evans, J. P., Blom, A. W., Sayers, A., and Whitehouse, M. R. (2019b). How long does a knee replacement last? A systematic review and meta-analysis of case series and national registry reports with more than 15 years of follow-up. Lancet 393, 655-663. doi: 10.1016/S0140-6736(18)32531-5

Feng, W., Geng, Z., Li, Z., Cui, Z., Zhu, S., Liang, Y., et al. (2016). Controlled release behaviour and antibacterial effects of antibiotic-loaded titania nanotubes. Mater. Sci. Eng. C Mater. Biol. Appl. 62, 105-112. doi: 10.1016/j.msec.2016. 01.046

Fisher, J. (2005). The role of macrophages in osteolysis of total joint replacement. Biomaterials 26, 1271-1286. doi: 10.1016/j.biomaterials.2004.04.035

Frojdo, S. (2008). Resveratrol: one molecule, many targets. IUBMB Life 60, $323-$ 332. doi: $10.1002 /$ iub.47

Gallazzi, E. (2018). Bearing surfaces in primary total hip arthroplasty. EFORT Open Rev. 3, 217-224. doi: 10.1302/2058-5241.3.180300

Gallo, J. (2019). Periprosthetic osteolysis: mechanisms, prevention and treatment. J. Clin. Med. 8:2091. doi: 10.3390/jcm8122091

Gamble, D., Jaiswal, P. K., Lutz, I., and Johnston, K. D. (2017). The use of ceramics in total hip arthroplasty. Ortho. Theum. 4:555636.

Gibon, E., Amanatullah, D. F., Loi, F., Pajarinen, J., Nabeshima, A., Yao, Z., et al. (2017a). The biological response to orthopaedic implants for joint replacement: part I: metals. J. Biomed. Mater. Res. B Appl. Biomater. 105, 2162-2173. doi: 10.1002/jbm.b.33734

Gibon, E., Cordova, L. A., Lu, L., Lin, T. H., Yao, Z., Hamadouche, M., et al. (2017b). The biological response to orthopedic implants for joint replacement. Ii: polyethylene, ceramics, pmma, and the foreign body reaction. J. Biomed. Mater. Res. B Appl. Biomater. 105, 1685-1691. doi: 10.1002/jbm.b.33676

Gill, H. S., Grammatopoulos, G., Adshead, S., Tsialogiannis, E., and Tsiridis, E. (2012). Molecular and immune toxicity of cocr nanoparticles in mom hip arthroplasty. Trends Mol. Med. 18, 145-155. doi: 10.1016/j.molmed.2011. 12.002

Goodman, S. B. (2007). Wear particles, periprosthetic osteolysis and the immune system. Biomaterials 28, 5044-5048. doi: 10.1016/j.biomaterials.2007.06.035

Goodman, S. B. (2014). Role of macrophages in the biological reaction to wear debris from joint replacements. J. Long Term. Eff. Med. Implants 24, 259-265. doi: 10.1615/jlongtermeffmedimplants.2014010562

Goodman, S. B., Gallo, J., Gibon, E., and Takagi, M. (2020). Diagnosis and management of implant debris-associated inflammation. Expert. Rev. Med. Devices 17, 41-56. doi: 10.1080/17434440.2020.1702024

Goodman, S. B., Gibon, E., Pajarinen, J., Lin, T. H., Keeney, M., Ren, P. G., et al. (2014). Novel biological strategies for treatment of wear particle-induced periprosthetic osteolysis of orthopaedic implants for joint replacement. J. R. Soc. Interface 11:20130962. doi: 10.1098/rsif.2013.0962

Gordon, A., Greenfield, E. M., Eastell, R., Kiss-Toth, E., and Wilkinson, J. M. (2010). Individual susceptibility to periprosthetic osteolysis is associated with altered patterns of innate immune gene expression in response to pro-inflammatory stimuli. J. Orthop. Res. 28, 1127-1135. doi: 10.1002/jor. 21135

Granchi, D., Savarino, L. M., Ciapetti, G., and Baldini, N. (2018). Biological effects of metal degradation in hip arthroplasties. Crit. Rev. Toxicol. 48, 170-193. doi: 10.1080/10408444.2017.1392927

Granchi, D., Savarino, L., Ciapetti, G., Cenni, E., Rotini, R., Mieti, M., et al. (2003). Immunological changes in patients with primary osteoarthritis of the hip after total joint replacement. J. Bone Joint Surg. Br. 85, 758-764. doi: 10.1302/0301620x.85b5.13729
Hachim, D., LoPresti, S. T., Yates, C. C., and Brown, B. N. (2017). Shifts in macrophage phenotype at the biomaterial interface via il-4 eluting coatings are associated with improved implant integration. Biomaterials 112, 95-107. doi: 10.1016/j.biomaterials.2016.10.019

Haleem, A. (2018). Prosthetic joint infections: an update. Curr. Infect Dis. Rep. 20:15. doi: 10.1007/s11908-018-0622-0

Hamadouche, M., Boutin, P., Daussange, J., Bolander, M. E., and Sedel, L. (2002). Alumina-on-alumina total hip arthroplasty: a minimum 18.5-year follow-up study. J. Bone Joint Surg. Am. 84, 69-77. doi: 10.2106/00004623-20020100000011

Hamidi, M., Harun, W. S. W., Samykano, M., Ghani, S. A. C., Ghazalli, Z., Ahmad, F., et al. (2017). A review of biocompatible metal injection moulding process parameters for biomedical applications. Mater. Sci. Eng. C Mater. Biol. Appl. 78, 1263-1276. doi: 10.1016/j.msec.2017.05.016

Han, J. D. (2001). Suppressive effects of interleukin-4 and interleukin-10 on the production of proinflammatory cytokines induced by titanium-alloy particles. J. Biomed. Mater. Res. 58, 531-536. doi: 10.1002/jbm.1051

Hannouche, D., Hamadouche, M., Nizard, R., Bizot, P., Meunier, A., and Sedel, L. (2005). Ceramics in total hip replacement. Clin. Orthop. Relat. Res. 430, 62-71. doi: 10.1097/01.blo.0000149996.919740.83

Hobza, M., Milde, D., Slobodova, Z., and Gallo, J. (2020). The number of lymphocytes increases in the periprosthetic tissues with increasing time of implant service in non-metal-on-metal total joint arthroplasties: a role of metallic byproducts?. Biomed. Pap. Med. Fac. Univ. Palacky Olomouc Czech. Repub. 164. doi: 10.5507/bp.2020.019

Holding, C. A., Findlay, D. M., Stamenkov, R., Neale, S. D., Lucas, H., Dharmapatni, A. S., et al. (2006). The correlation of rank, rankl and tnfalpha expression with bone loss volume and polyethylene wear debris around hip implants. Biomaterials 27, 5212-5219. doi: 10.1016/j.biomaterials.2006.05.054

Horowitz, S. M., Algan, S. A., and Purdon, M. A. (1996). Pharmacologic inhibition of particulate-induced bone resorption. J. Biomed. Mater. Res. 31, 91-96. doi: 10.1002/(SICI)1097-4636(199605)31:1<91::AID-JBM11<3.0.CO;2-P

Howard, D. P., Wall, P. D. H., Fernandez, M. A., Parsons, H., and Howard, P. W. (2017). Ceramic-on-ceramic bearing fractures in total hip arthroplasty: an analysis of data from the national joint registry. Bone Joint J. 99-B, 1012-1019. doi: 10.1302/0301-620X.99B8.BJJ-2017-0019.R1

Hu, X., Yin, Z., Chen, X., Jiang, G., Yang, D., Cao, Z., et al. (2020). Tussilagone inhibits osteoclastogenesis and periprosthetic osteolysis by suppressing the nfkappab and p38 mapk signaling pathways. Front. Pharmacol. 11:385. doi: 10. 3389/fphar.2020.00385

Huang, Z., Ma, T., Ren, P. G., Smith, R. L., and Goodman, S. B. (2010). Effects of orthopedic polymer particles on chemotaxis of macrophages and mesenchymal stem cells. J. Biomed. Mater. Res. A 94, 1264-1269. doi: 10.1002/jbm.a.32803

Huk, O. L., Zukor, D. J., Antoniou, J., and Petit, A. (2003). Effect of pamidronate on the stimulation of macrophage tnf-alpha release by ultra-high-molecularweight polyethylene particles: a role for apoptosis. J. Orthop. Res. 21, 81-87. doi: 10.1016/S0736-0266(02)00099-2

Inacio, M. C. S., Cafri, G., Paxton, E. W., Kurtz, S. M., and Namba, R. S. (2013). Alternative bearings in total knee arthroplasty: risk of early revision compared to traditional bearings an analysis of 62,177 primary cases. Acta Orthopaedica 84, 145-152. doi: 10.3109/17453674.2013.784660

Jagga, S., Sharma, A. R., Bhattacharya, M., Chakraborty, C., and Lee, S. S. (2019). Influence of single nucleotide polymorphisms (snps) in genetic susceptibility towards periprosthetic osteolysis. Genes Genomics 41, 1113-1125. doi: 10.1007/ s13258-019-00845-3

Jamsen, E., Pajarinen, J., Kouri, V. P., Rahikkala, A., Goodman, S. B., Manninen, M., et al. (2020). Tumor necrosis factor primes and metal particles activate the nlrp3 inflammasome in human primary macrophages. Acta Biomater. doi: 10.1016/j.actbio.2020.03.017

Jiang, J., Jia, T., Gong, W., Ning, B., Wooley, P. H., and Yang, S. Y. (2016). Macrophage polarization in il-10 treatment of particle-induced inflammation and osteolysis. Am. J. Pathol. 186, 57-66. doi: 10.1016/j.ajpath.2015.09.006

Kandahari, A. M., Yang, X., Laroche, K. A., Dighe, A. S., Pan, D., and Cui, Q. (2016). A review of uhmwpe wear-induced osteolysis: the role for early detection of the immune response. Bone Res. 4:16014. doi: 10.1038/boneres.2016.14

Kang, B. J., Ha, Y. C., Ham, D. W., Hwang, S. C., Lee, Y. K., and Koo, K. H. (2015). Third-generation alumina-on-alumina total hip arthroplasty: 14 to 16-year follow-up study. J. Arthroplasty 30, 411-415. doi: 10.1016/j.arth.2014.09.020 
Karin, M., Yamamoto, Y., and Wang, Q. M. (2004). The ikk nf-kappa b system: a treasure trove for drug development. Nat. Rev. Drug. Discov. 3, 17-26. doi: $10.1038 / \operatorname{nrd} 1279$

Katz, J. N. (2012). Total knee arthroplasty on the rise in younger patients: are we sure that past performance will guarantee future success? Arthritis Rheum. 64, 339-341. doi: 10.1002/art.33371

Kaufman, A. M., Alabre, C. I., Rubash, H. E., and Shanbhag, A. S. (2008). Human macrophage response to uhmwpe, tialv, cocr, and alumina particles: analysis of multiple cytokines using protein arrays. J. Biomed. Mater. Res. A 84, 464-474. doi: $10.1002 /$ jbm.a.31467

Kubes, P. (2020). Damps, pamps, and lamps in immunity and sterile inflammation. Annu. Rev. Pathol. 15, 493-518. doi: 10.1146/annurev-pathmechdis-012419032847

Kumar, H., Kawai, T., and Akira, S. (2011). Pathogen recognition by the innate immune system. Int. Rev. Immunol. 30, 16-34. doi: 10.3109/08830185.2010. 529976

Kurtz, S. M., Lau, E., Ong, K., Zhao, K., Kelly, M., and Bozic, K. J. (2009). Future young patient demand for primary and revision joint replacement: national projections from 2010 to 2030. Clin. Orthop. Relat. Res. 467, 2606-2612. doi: 10.1007/s11999-009-0834-6

Kurtz, S., Ong, K., Lau, E., Mowat, F., and Halpern, M. (2007). Projections of primary and revision hip and knee arthroplasty in the united states from 2005 to 2030. J. Bone Joint Surg. Am. 89, 780-785. doi: 10.2106/JBJS.F.00222

Lahdeoja, T., Pajarinen, J., Kouri, V. P., Sillat, T., Salo, J., and Konttinen, Y. T. (2010). Toll-like receptors and aseptic loosening of hip endoprosthesisa potential to respond against danger signals? J. Orthop. Res. 28, 184-190. doi: 10.1002/jor.20979

Landgraeber, S., Jager, M., Jacobs, J. J., and Hallab, N. J. (2014). The pathology of orthopedic implant failure is mediated by innate immune system cytokines. Mediators Inflamm. 2014:185150. doi: 10.1155/2014/185150

Learmonth, I. D., Young, C., and Rorabeck, C. (2007). The operation of the century: total hip replacement. Lancet 370, 1508-1519. doi: 10.1016/S0140-6736(07) 60457-7

Li, Y., Yang, Y., Li, R., Tang, X., Guo, D., Qing, Y., et al. (2019). Enhanced antibacterial properties of orthopedic implants by titanium nanotube surface modification: a review of current techniques. Int. J. Nanomed. 14, 7217-7236. doi: 10.2147/IJN.S216175

Lin, T. H., Pajarinen, J., Sato, T., Loi, F., Fan, C., Cordova, L. A., et al. (2016). Nf-kappab decoy oligodeoxynucleotide mitigates wear particle-associated bone loss in the murine continuous infusion model. Acta Biomater. 41, 273-281. doi: 10.1016/j.actbio.2016.05.038

Lin, T. H., Tamaki, Y., Pajarinen, J., Waters, H. A., Woo, D. K., Yao, Z., et al. (2014). Chronic inflammation in biomaterial-induced periprosthetic osteolysis: Nf-kappab as a therapeutic target. Acta Biomater. 10, 1-10. doi: 10.1016/j.actbio. 2013.09.034

Lucarelli, M., Gatti, A. M., Savarino, G., Quattroni, P., Martinelli, L., Monari, E., et al. (2004). Innate defence functions of macrophages can be biased by nano-sized ceramic and metallic particles. Eur. Cytokine Netw. 15, 339-346.

Lum, Z. C., Shieh, A. K., and Dorr, L. D. (2018). Why total knees fail-a modern perspective review. World J. Orthop. 9, 60-64. doi: 10.5312/wjo.v9.i4.60

Luo, G., Li, Z., Wang, Y., Wang, H., Zhang, Z., Chen, W., et al. (2016). Resveratrol protects against titanium particle-induced aseptic loosening through reduction of oxidative stress and inactivation of nf-kappab. Inflammation 39, 775-785. doi: 10.1007/s10753-016-0306-6

Maalouf, N. M. (2012). Safety of bisphosphonates. Rheum. Dis. Clin. North Am. 38, 681-705. doi: 10.1016/j.rdc.2012.09.001

MacInnes, S. J., Del Vescovo, E., Kiss-Toth, E., Ollier, W. E., Kay, P. R., Gordon, A., et al. (2015). Genetic variation in inflammatory and bone turnover pathways and risk of osteolytic responses to prosthetic materials. J. Orthop. Res. 33, 193-198. doi: 10.1002/jor.22755

Mahon, O. R., O’Hanlon, S., Cunningham, C. C., McCarthy, G. M., Hobbs, C., Nicolosi, V., et al. (2018). Orthopaedic implant materials drive ml macrophage polarization in a spleen tyrosine kinase- and mitogen-activated protein kinasedependent manner. Acta Biomater. 65, 426-435. doi: 10.1016/j.actbio.2017. 10.041

Maitra, R., Clement, C. C., Scharf, B., Crisi, G. M., Chitta, S., Paget, D., et al. (2009). Endosomal damage and tlr2 mediated inflammasome activation by alkane particles in the generation of aseptic osteolysis. Mol. Immunol. 47, 175-184. doi: 10.1016/j.molimm.2009.09.023
Martinon, F., Burns, K., and Tschopp, J. (2002). The inflammasome: a molecular platform triggering activation of inflammatory caspases and processing of proil-beta. Mol. Cell 10, 417-426. doi: 10.1016/s1097-2765(02)00599-3

Matzinger, P. (1994). Tolerance, danger, and the extended family. Annu. Rev. Immunol. 12, 991-1045. doi: 10.1146/annurev.iy.12.040194.005015

Medzhitov, R. Janeway, and C. A. Jr. (1997). Innate immunity: the virtues of a nonclonal system of recognition. 91, 295-Ü298.doi: 10.1016/s0092-8674(00) 80412-2

Moreau, M. F., Guillet, C., Massin, P., Chevalier, S., Gascan, H., Basle, M. F., et al. (2007). Comparative effects of five bisphosphonates on apoptosis of macrophage cells in vitro. Biochem. Pharmacol. 73, 718-723. doi: 10.1016/j.bcp. 2006.09.031

Murray, P. J. (2017). Macrophage polarization. Annu. Rev. Physiol. 79, 541-566. doi: 10.1146/annurev-physiol-022516-034339

Naganuma, Y., Takakubo, Y., Hirayama, T., Tamaki, Y., Pajarinen, J., Sasaki, K., et al. (2016). Lipoteichoic acid modulates inflammatory response in macrophages after phagocytosis of titanium particles through toll-like receptor 2 cascade and inflammasomes. J. Biomed. Mater. Res. A 104, 435-444. doi: 10.1002/jbm.a.35581

Navarro, M., Michiardi, A., Castano, O., and Planell, J. A. (2008). Biomaterials in orthopaedics. J. R. Soc. Interface 5, 1137-1158. doi: 10.1098/rsif.2008.0151

Nich, C., Takakubo, Y., Pajarinen, J., Ainola, M., Salem, A., Sillat, T., et al. (2013). Macrophages-key cells in the response to wear debris from joint replacements. J. Biomed. Mater. Res. A 101, 3033-3045. doi: 10.1002/jbm.a.34599

Ning, C. Y., Zhou, L., and Tan, G. X. (2016). Fourth-generation biomedical materials. Mater. Today 19, 2-3. doi: 10.1016/j.mattod.2015. 11.005

Oblak, A., Pohar, J., and Jerala, R. (2015). Md-2 determinants of nickel and cobaltmediated activation of human tlr4. PLoS One 10:e0120583. doi: 10.1371/journal. pone. 0120583

O’Neill, L. A., Golenbock, D., and Bowie, A. G. (2013). The history of toll-like receptors - redefining innate immunity. Nat. Rev. Immunol. 13, 453-460. doi: $10.1038 /$ nri3446

Oonishi, H., Ueno, M., Kim, S. C., Oonishi, H., Iwamoto, M., and Kyomoto, M. (2009). Ceramic versus cobalt-chrome femoral components; wear of polyethylene insert in total knee prosthesis. J. Arthroplasty 24, 374-382. doi: 10.1016/j.arth.2007.10.021

Pajarinen, J., Cenni, E., Savarino, L., Gomez-Barrena, E., Tamaki, Y., Takagi, M., et al. (2010). Profile of toll-like receptor-positive cells in septic and aseptic loosening of total hip arthroplasty implants. J. Biomed. Mater. Res. A 94, 84-92. doi: 10.1002/jbm.a.32674

Pajarinen, J., Jamsen, E., Konttinen, Y. T., and Goodman, S. B. (2014). Innate immune reactions in septic and aseptic osteolysis around hip implants. J. Long Term Eff. Med. Implants 24, 283-296. doi: 10.1615/jlongtermeffmedimplants. 2014010564

Pandey, R., Quinn, J. M., Sabokbar, A., and Athanasou, N. A. (1996). Bisphosphonate inhibition of bone resorption induced by particulate biomaterial-associated macrophages. Acta Orthop. Scand. 67, 221-228. doi: $10.3109 / 17453679608994677$

Parvizi, J. (2015). Biological response to prosthetic debris. World J. Orthop. 6, 172-189. doi: 10.5312/wjo.v6.i2.172

Paulus, A. C., Frenzel, J., Ficklscherer, A., Rossbach, B. P., Melcher, C., Jansson, V., et al. (2014). Polyethylene wear particles induce tlr 2 upregulation in the synovial layer of mice. J. Mater. Sci. Mater. Med. 25, 507-513. doi: 10.1007/ s10856-013-5095-y

Pearl, J. I., Ma, T., Irani, A. R., Huang, Z., Robinson, W. H., Smith, R. L., et al. (2011). Role of the toll-like receptor pathway in the recognition of orthopedic implant wear-debris particles. Biomaterials 32, 5535-5542. doi: 10. 1016/j.biomaterials.2011.04.046

Petsatodis, G. E., Papadopoulos, P. P., Papavasiliou, K. A., Hatzokos, I. G., Agathangelidis, F. G., and Christodoulou, A. G. (2010). Primary cementless total hip arthroplasty with an alumina ceramic-on-ceramic bearing: results after a minimum of twenty years of follow-up. J. Bone Joint Surg. Am. 92, 639-644. doi: 10.2106/JBJS.H.01829

Prasad, K., Bazaka, O., Chua, M., Rochford, M., Fedrick, L., Spoor, J., et al. (2017). Metallic biomaterials: current challenges and opportunities. Materials 10:884. doi: 10.3390/ma10080884

Prieto-Alhambra, D., Lalmohamed, A., Abrahamsen, B., Arden, N. K., de Boer, A., Vestergaard, P., et al. (2014). Oral bisphosphonate use and total knee/hip 
implant survival: validation of results in an external population-based cohort. Arthritis Rheumatol. 66, 3233-3240. doi: 10.1002/art.38789

Purdue, P. E., Koulouvaris, P., Potter, H. G., Nestor, B. J., and Sculco, T. P. (2007). The cellular and molecular biology of periprosthetic osteolysis. Clin. Orthop. Relat. Res. 454, 251-261. doi: 10.1097/01.blo.0000238813.95035.1b

Quinn, J., Joyner, C., Triffitt, J. T., and Athanasou, N. A. (1992). Polymethylmethacrylate-induced inflammatory macrophages resorb bone. J. Bone Joint Surg. Br. 74, 652-658. doi: 10.1302/0301-620x.74b5.1527108

Raghavan, B., Martin, S. F., Esser, P. R., Goebeler, M., and Schmidt, M. (2012). Metal allergens nickel and cobalt facilitate tlr4 homodimerization independently of $\mathrm{md} 2$. EMBO Rep. 13, 1109-1115. doi: $10.1038 /$ embor.2012.155

Rao, A. J., Gibon, E., Ma, T., Yao, Z., Smith, R. L., and Goodman, S. B. (2012). Revision joint replacement, wear particles, and macrophage polarization. Acta Biomater. 8, 2815-2823. doi: 10.1016/j.actbio.2012.03.042

Rao, A. J., Nich, C., Dhulipala, L. S., Gibon, E., Valladares, R., Zwingenberger, S., et al. (2013). Local effect of il-4 delivery on polyethylene particle induced osteolysis in the murine calvarium. J. Biomed. Mater. Res. A 101, 1926-1934. doi: 10.1002/jbm.a.34486

Ravi, B., Jenkinson, R., O'Heireamhoin, S., Austin, P. C., Aktar, S., Leroux, T. S., et al. (2019). Surgical duration is associated with an increased risk of periprosthetic infection following total knee arthroplasty: a population-based retrospective cohort study. EClinicalMedicine 16, 74-80. doi: 10.1016/j.eclinm. 2019.09.015

Ribeiro-da-Silva, M., Vasconcelos, D. M., Alencastre, I. S., Oliveira, M. J., Linhares, D., Neves, N., et al. (2018). Interplay between sympathetic nervous system and inflammation in aseptic loosening of hip joint replacement. Sci. Rep. 8:16044. doi: 10.1038/s41598-018-33360-8

Sabokbar, A., Pandey, R., Quinn, J. M., and Athanasou, N. A. (1998). Osteoclastic differentiation by mononuclear phagocytes containing biomaterial particles. Arch. Orthop. Trauma Surg. 117, 136-140. doi: 10.1007/s004020050213

Sakellariou, V. I., Sculco, P., Poultsides, L., Wright, T., and Sculco, T. P. (2013). Highly cross-linked polyethylene may not have an advantage in total knee arthroplasty. HSS J. 9, 264-269. doi: 10.1007/s11420-013-9352-x

Samelko, L., Caicedo, M. S., Lim, S. J., Della-Valle, C., Jacobs, J., and Hallab, N. J. (2013). Cobalt-alloy implant debris induce hif-1alpha hypoxia associated responses: a mechanism for metal-specific orthopedic implant failure. PLoS One 8:e67127. doi: 10.1371/journal.pone.0067127

Samelko, L., Landgraeber, S., McAllister, K., Jacobs, J., and Hallab, N. J. (2016). Cobalt alloy implant debris induces inflammation and bone loss primarily through danger signaling, not tlr4 activation: implications for damp-ening implant related inflammation. PLoS One 11:e0160141. doi: 10.1371/journal. pone. 0160141

Sato, T., Pajarinen, J., Lin, T. H., Tamaki, Y., Loi, F., Egashira, K., et al. (2015). Nf-kappab decoy oligodeoxynucleotide inhibits wear particle-induced inflammation in a murine calvarial model. J. Biomed. Mater. Res. A 103, 3872-3878. doi: 10.1002/jbm.a.35532

Schalock, P. C. (2017). Metal hypersensitivity reactions to orthopedic implants. Dermatol. Ther. 7, 53-64. doi: 10.1007/s13555-016-0162-1

Schwarz, E. M. (2014). Are biologic treatments a potential approach to wearand corrosion-related problems? Clin. Orthop. Rel. Res. 472, 3740-3746. doi: 10.1007/s11999-014-3765-9

Sharkey, P. F., Lichstein, P. M., Shen, C., Tokarski, A. T., and Parvizi, J. (2014). Why are total knee arthroplasties failing today-has anything changed after 10 years? J. Arthroplasty 29, 1774-1778. doi: 10.1016/j.arth.2013.07.024

Shi, J. Y., Zhu, W. C., Liang, S. H., Li, H. L., and Li, S. M. (2019). Cross-linked versus conventional polyethylene for long-term clinical outcomes after total hip arthroplasty: a systematic review and meta-analysis. J. Invest. Surg. 2, 1-11. doi: $10.1080 / 2019.1606370$.

Shi, M., Chen, L., Wu, H., Wang, Y., Wang, W., Zhang, Y., et al. (2018). Effect of bisphosphonates on periprosthetic bone loss after total knee arthroplasty: a meta-analysis of randomized controlled trials. BMC Musculoskelet Disord. 19:177. doi: 10.1186/s12891-018-2101-Z

Shi, M., Chen, L., Xin, Z., Wang, Y., Wang, W., and Yan, S. (2018b). Bisphosphonates for the preservation of periprosthetic bone mineral density after total joint arthroplasty: A meta-analysis of 25 randomized controlled trials. Osteoporos Int. 29,1525Ü1537. doi: 10.1007/s00198-018-4488-7
Shiratori, T., Kyumoto-Nakamura, Y., Kukita, A., Uehara, N., Zhang, J., Koda, K., et al. (2018). Il-1beta induces pathologically activated osteoclasts bearing extremely high levels of resorbing activity: a possible pathological subpopulation of osteoclasts, accompanied by suppressed expression of kindlin-3 and talin-1. J. Immunol. 200, 218-228. doi: 10.4049/jimmunol.160 2035

Skytta, E. T., Jarkko, L., Antti, E., Huhtala, H., and Ville, R. (2011). Increasing incidence of hip arthroplasty for primary osteoarthritis in 30- to 59-year-old patients. Acta Orthop. 82, 1-5. doi: 10.3109/17453674.2010.548029

Solarino, G., Piconi, C., De Santis, V., Piazzolla, A., and Moretti, B. (2017). Ceramic total knee arthroplasty: ready to go? Joints 5, 224-228. doi: 10.1055/s-00371607428

Su, J., Wei, Y., Li, X. M., Diao, Y. P., Liu, H. G., and Zhang, L. (2018). Efficacy of risedronate in improving bone mineral density in patients undergoing total hip arthroplasty: a meta-analysis of randomized controlled trials. Medicine 97:e13346. doi: 10.1097/MD.0000000000013346

Sukur, E., Akman, Y. E., Ozturkmen, Y., and Kucukdurmaz, F. (2016). Particle disease: a current review of the biological mechanisms in periprosthetic osteolysis after hip arthroplasty. Open Orthop. J. 10, 241-251. doi: 10.2174/ 1874325001610010241

Swanson, T. V., Peterson, D. J., Seethala, R., Bliss, R. L., and Spellmon, C. A. (2010). Influence of prosthetic design on squeaking after ceramic-on-ceramic total hip arthroplasty. J. Arthroplasty 25(6 Suppl.), 36-42. doi: 10.1016/j.arth.2010.04. 032

Takagi, M., Tamaki, Y., Hasegawa, H., Takakubo, Y., Konttinen, L., Tiainen, V. M., et al. (2007). Toll-like receptors in the interface membrane around loosening total hip replacement implants. J. Biomed. Mater. Res. A. 81, 1017-1026. doi: 10.1002/jbm.a.31235

Terkawi, M. A., Hamasaki, M., Takahashi, D., Ota, M., Kadoya, K., Yutani, T., et al. (2018). Transcriptional profile of human macrophages stimulated by ultrahigh molecular weight polyethylene particulate debris of orthopedic implants uncovers a common gene expression signature of rheumatoid arthritis. Acta Biomater. 65, 417-425. doi: 10.1016/j.actbio.2017.11.001

Thiele, K., Perka, C., Matziolis, G., Mayr, H. O., Sostheim, M., and Hube, R. (2015). Current failure mechanisms after knee arthroplasty have changed: polyethylene wear is less common in revision surgery. J. Bone Joint Surg. Am. 97, 715-720. doi: 10.2106/JBJS.M.01534

Tian, Q., Zhao, Y., Mundra, J. J., Gonzalez-Gugel, E., Jian, J., Uddin, S. M., et al. (2014). Three tnfr-binding domains of pgrn act independently in inhibition of tnf-alpha binding and activity. Front. Biosci. 19:1176-1185. doi: 10.2741/4274

Trindade, M. C., Nakashima, Y., Lind, M., Sun, D. H., Goodman, S. B., Maloney, W. J., et al. (1999). Interleukin-4 inhibits granulocyte-macrophage colonystimulating factor, interleukin-6, and tumor necrosis factor-alpha expression by human monocytes in response to polymethylmethacrylate particle challenge in vitro. J. Orthop. Res. 17, 797-802. doi: 10.1002/jor.1100170602

Tschopp, J. (2010). The inflammasomes. Cell 140, 821-832. doi: 10.1016/j.cell.2010. 01.040

Tuan, W. H., Chen, R. Z., Wang, T. C., Cheng, C. H., and Kuo, P. S. (2002). Mechanical properties of al2o3/zro2 composites. J. Eur. Ceram. Soc. 22, 28272833. doi: 10.1016/S0955-2219(02)00043-2

Ulrich-Vinther, M., Carmody, E. E., Goater, J. J., Sb, K., O’Keefe, R. J., and Schwarz, E. M. (2002). Recombinant adeno-associated virus-mediated osteoprotegerin gene therapy inhibits wear debris-induced osteolysis. J. Bone Joint Surg. Am. 84, 1405-1412. doi: 10.2106/00004623-200208000-00016

Valladares, R. D., Nich, C., Zwingenberger, S., Li, C., Swank, K. R., Gibon, E., et al. (2014). Toll-like receptors- 2 and 4 are overexpressed in an experimental model of particle-induced osteolysis. J. Biomed. Mater. Res. A 102, 3004-3011. doi: 10.1002/jbm.a.34972

Vanhegan, I. S., Malik, A. K., Jayakumar, P., Ul Islam, S., and Haddad, F. S. (2012). A financial analysis of revision hip arthroplasty: the economic burden in relation to the national tariff. J. Bone Joint Surg. Br. 94, 619-623. doi: 10.1302/0301620X.94B5.27073

Venereau, E., Ceriotti, C., and Bianchi, M. E. (2015). Damps from cell death to new life. Front. Immunol. 6:422. doi: 10.3389/fimmu.2015.00422

Wada, T., Nakashima, T., Hiroshi, N., and Penninger, J. M. (2006). Rankl-rank signaling in osteoclastogenesis and bone disease. Trends Mol. Med. 12, 17-25. doi: 10.1016/j.molmed.2005.11.007 
Weber, M., Renkawitz, T., Voellner, F., Craiovan, B., Greimel, F., Worlicek, M., et al. (2018). Revision surgery in total joint replacement is cost-intensive. Biomed. Res. Int. 2018:8987104. doi: 10.1155/2018/8987104

Yan, Z., Tian, X., Zhu, J., Lu, Z., Yu, L., Zhang, D., et al. (2018). Metformin suppresses uhmwpe particle-induced osteolysis in the mouse calvaria by promoting polarization of macrophages to an antiinflammatory phenotype. Mol. Med. 24:20. doi: 10.1186/s10020-0180013-x

Yang, C. L., Sun, Y. H., Yu, W. H., Yin, X. Z., Weng, J., and Feng, B. (2018). Modulation of macrophage phenotype through controlled release of interleukin-4 from gelatine coatings on titanium surfaces. Eur. Cell Mater 36, 15-29. doi: 10.22203/eCM.v036a02

Zhao, Y. P., Wei, J. L., Tian, Q. Y., Liu, A. T., Yi, Y. S., Einhorn, T. A., et al. (2016). Progranulin suppresses titanium particle induced inflammatory osteolysis by targeting tnfalpha signaling. Sci. Rep. 6:20909. doi: 10.1038/srep2 0909

Conflict of Interest: The authors declare that the research was conducted in the absence of any commercial or financial relationships that could be construed as a potential conflict of interest.

Copyright (c) 2020 Couto, Vasconcelos, Sousa, Sousa, Conceição, Neto, Lamghari and Alves. This is an open-access article distributed under the terms of the Creative Commons Attribution License (CC BY). The use, distribution or reproduction in other forums is permitted, provided the original author(s) and the copyright owner(s) are credited and that the original publication in this journal is cited, in accordance with accepted academic practice. No use, distribution or reproduction is permitted which does not comply with these terms. 